\title{
Orodispersible Films of Meloxicam Inclusion Complexes for Bioavailability Enhancement: Optimization and Development through Quality by Design Approach
}

\author{
Archana Nerella ${ }^{1, *}$, MV Nagabhushanam $^{2}$ \\ 1 Department of Pharmaceutics, Acharya Nagarjuna University, Guntur, Andhra Pradesh, INDIA \\ ${ }^{2}$ Hindu College of Pharmacy, Guntur, Andhra Pradesh, INDIA.
}

\begin{abstract}
Background: Owing to overcome the dissolution limited bioavailability of Meloxicam, the current research involves the development of Orodispersible films using Meloxicam by employing Quality by Design. Methods: In this work, the Meloxicam oral dispersible films were formulated by solvent casting method by altering three formulation factors viz. amount of film former, amount of the plasticizer, PEG 400 and type of film former (HPMC E3, HPMC E5, HPMC E15). Historical data designing under response surface methodology was selected as the experimental design. Disintegration time, dissolution of Meloxicam after 5 mins, folding endurance and tensile strength of the orodispersible films were taken as the responses. Results: All the formulations were found to have favorable tensile strength and folding endurance. The disintegration time values were found to be in a range of 9-15 sec, the values of amount of Meloxicam dissolved after $5 \mathrm{~min}$ were found to be in the range of $48-98 \%$. The data obtained from the responses were statistically treated using ANOVA and the effect of the formulation factors were found to be
\end{abstract}

significant. Conclusion: The optimization of these formulations indicated that a combined film former of $140 \mathrm{mg}$ of HPMC E15 and $50 \mathrm{mg}$ of HPMC E3 with $25 \mathrm{~mL}$ plasticizer was found to be the optimized formulation. The films prepared at this combination showed disintegration time of $8 \mathrm{sec}$, drug release of $66.5 \%$ after 5 min which indicate that the formulated Meloxicam orodispersible films were successfully optimized and developed.

Key words: Oro-dispersible films, Dissolution enhancement, Historical data designing, optimization, ANOVA, Response surface methodology

Correspondence

Assoc. prof. Archana Nerella

Research Scholar, Department of Pharmaceutics, University College of Pharmaceutical Sciences, Acharya Nagarjuna University, Nagarjuna Nagar, Guntur-52251, Andhra Pradesh, INDIA.

Email id: archana.nerella@gmail.com

DOI: $10.5530 /$ ijpi.2021.4.75

\section{INTRODUCTION}

Meloxicam is a non-steroidal anti-inflammatory drug which is used in the treatment of osteoarthritis and rheumatoid arthritis in adults and juvenile rheumatoid arthritis in pediatrics. It is used to relieve the musculoskeletal conditions and also neuropathic pain. The halflife of meloxicam is $20 \mathrm{hr}^{1}$ which is longer than most of the other NSAIDs, which helps to give a single dose of the drug without a need for formulation into a sustained/extended-release formulation. ${ }^{2}$ It acts by inhibiting the COX-2 enzyme thereby reducing the risk of adverse gastrointestinal effects caused in most of the NSAIDs. ${ }^{3}$ The solubility of meloxicam is practically insoluble in water ${ }^{4}$ making it a poor watersoluble drug which thereby leads to dissolution limited bioavailability of the drug. Owing to this problem, meloxicam has to be developed into a dosage form where its dissolution is enhanced.

Among all the routes of drug delivery, oral route has always found to has a significant ease of administration, patient compliance and also versatile in formulating several drugs as oral dosage forms. Intense research and development in the oral drug delivery show a promising transition from tablet/capsules to oral disintegrating tablets to oral dispersible films/strips. ${ }^{5}$ The orodispersible films (ODFs) have been found to show a promising advantage than other oral dosage forms due to their ease of ingestion, patient compliance, high stability and also the versatility in incorporating higher amounts of drug; also, a rapid disintegration and an enhanced drug dissolution owing to the increase in the drug bioavailability. Several researches on these ODFs like Nishimura M et.al.2009, ${ }^{6}$ Kulkarni KP et.al. $2011^{7}$ and Saini S et.al
$2012 .^{8}$ have elucidated the significant increase in the drug dissolution when formulated as ODFs owing to enhancement in the bioavailability. The widely carried literature review signifies the scope of development of oral/mouth dispersing films by using different hydrophilic polymers which act as film formers.

Among various methods of enhancement of the bioavailability, formation of cyclodextrin complexes (CDS) has been proved to be advantageous, as they are used as complexing agents with the poor water-soluble drugs to increase their aqueous solubility, thereby enhancing their dissolution and bioavailability. ${ }^{9} \mathrm{CD}$ s have been used to reduce or prevent gastrointestinal irritation, improve patient compliance by reducing the unpleasant tastes or smell, prevent various drug interactions and also in the conversion of oils and liquid drugs into microcrystalline or amorphous powders. ${ }^{10}$ The current work includes the formulation of Meloxicam ODFs by solvent casting method, in which initially the $\gamma$-cyclodextrin complexes ${ }^{11}$ are formulated using maltodextrin ${ }^{12}$ which are then prepared as the mouth dissolving films.

The current study involves the design of experiment using Design Expert software. Historical data designing under response surface methodology has been used to design the formulations. HPMC E3, HPMC E5 AND HPMC E15 were the three film formers used at different concentrations. The independent factors taken in this work are type of film formers, concentration of film formers and the concentration of plasticizers. Disintegration time (DT), percent of drug dissolved after 5 min (D5\%),

This is an open access article distributed under the terms of the Creative Commons Attribution-NonCommercial-ShareAlike 4.0 License, which allows others to remix, tweak, and build upon the work non-commercially, as long as the author is credited and the new creations are licensed under the identical terms. 
tensile strength and folding endurance of the ODFs were taken as response variables which thereby determine the desired quality of the ODFs. The developed films were characterized for different physical characteristics and the responses, the results of which were statistically treated with ANOVA.

\section{MATERIALS AND METHODS}

\section{Materials}

Meloxicam was procured from Hetero Drugs Pvt. Ltd, Visakhapatnam; HPMC E3, HPMC E5, HPMC E15 and PEG 400 were acquired from Sigma Chemicals Co.; Maltodextrin, aspartame, citric acid and pineapple flavor were purchased from SD Fine Chemicals, Mumbai. All other chemicals used in the current work are of analytical grade.

\section{Design of experiment}

Three formulation parameters were selected as the independent factors viz. A: amount of film former (140-260mg), B: amount of plasticizer (PEG 400, 5-25mL) and C: Type of HPMC polymer used. The responses were the four critical quality attributes of the MX-ODFs viz. R1: Disintegration time, R2: Tensile strength of the film, R3: Folding endurance and R4: Amount of drug dissolved after $5 \mathrm{~min}$. Historical data design under response surface methodology was employed as the experimental design and has been executed using StatEase Design Expert software. 30 different runs as the combinations of the factors with their levels (Table 1) were used to formulate the MX-ODFs.

\section{Development of meloxicam oral dispersible films}

The $\gamma$-cyclodextrin complexes ${ }^{13}$ were formulated into mouth dissolving films by solvent casting method ${ }^{14}$ by employing quality by design (QbD) based approach. Film forming polymers of different grades of HPMC (140-260 mg) and Maltodextrin (50 mg) based on the formulation runs as shown in Table 1 were soaked for $24 \mathrm{hr}$ to ensure complete hydration. The solution was stirred on a magnetic stirrer at $50 \mathrm{rpm}$ for $2 \mathrm{hr}$, PEG 400 (5-25 mL) was added and stirring was continued for $30 \mathrm{~min}$ at $50 \mathrm{rpm}$. This process ensures the formation of cyclodextrin complexes. In this process, all the water-soluble ingredients $(0.1 \mathrm{~mL}$ pineapple flavor, $2 \mathrm{mg}$ citric acid, $8 \mathrm{mg}$ Aspartame and $24.75 \mathrm{mg}$ Meloxicam) were dissolved in an aqueous solvent to form a clear solution for each formulation. This solution was added to the cyclodextrin complex solution upon constant stirring till the formation of a homogenous solution which was poured onto a dry petri dish and further dried at $45^{\circ} \mathrm{C}$ for $6 \mathrm{hr}$. The obtained film was cut carefully into a shape of $4 \mathrm{~cm}^{2}$ (equivalent to $7.5 \mathrm{mg}$ Meloxicam) which were further stored and subjected to different characterization studies.

\section{Appearance and Thickness}

The surface appearance of the ODFs was carried by visualization for a transparent or semi-transparent glossy smooth texture film. Using a micrometer screw-gauge, the thickness of the MX-ODFs was measured at five different points and the obtained results were reported as their mean value. ${ }^{15}$

\section{Folding endurance}

By counting the number of times, the film can be folded repetitively until it broke, the folding endurance ${ }^{16}$ of the ODFs was determined. Texture analyzer was used to determine the tensile strength of the ODFs.

\section{Tensile strength}

The maximum stress applied to a point at which the film specimen breaks, determines the tensile strength. ${ }^{17,18}$ It is calculated from the
Table 1: Combination of factors and their levels with the formulation compositions.

\begin{tabular}{|c|c|c|c|c|c|c|c|c|c|}
\hline \multirow{2}{*}{ 힝 } & \multirow{2}{*}{ 올 ิㅡㅁ } & \multicolumn{3}{|c|}{ HPMC (mg) } & \multirow{2}{*}{ 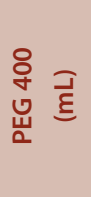 } & \multirow{2}{*}{ 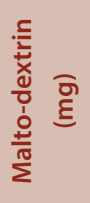 } & \multirow{2}{*}{ 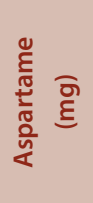 } & \multirow{2}{*}{ 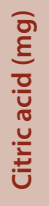 } & \multirow{2}{*}{ 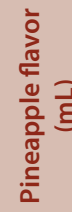 } \\
\hline & & E3 & E5 & E15 & & & & & \\
\hline $\mathrm{F} 1$ & 24.75 & 260 & - & - & 5 & 50 & 8 & 2 & 0.1 \\
\hline F2 & 24.75 & 230 & - & - & 10 & 50 & 8 & 2 & 0.1 \\
\hline F3 & 24.75 & 200 & - & - & 15 & 50 & 8 & 2 & 0.1 \\
\hline F4 & 24.75 & 170 & - & - & 20 & 50 & 8 & 2 & 0.1 \\
\hline F5 & 24.75 & 140 & - & - & 25 & 50 & 8 & 2 & 0.1 \\
\hline F6 & 24.75 & - & 260 & - & 5 & 50 & 8 & 2 & 0.1 \\
\hline F7 & 24.75 & - & 230 & - & 10 & 50 & 8 & 2 & 0.1 \\
\hline F8 & 24.75 & - & 200 & - & 15 & 50 & 8 & 2 & 0.1 \\
\hline F9 & 24.75 & - & 170 & - & 20 & 50 & 8 & 2 & 0.1 \\
\hline F10 & 24.75 & - & 140 & - & 25 & 50 & 8 & 2 & 0.1 \\
\hline F11 & 24.75 & - & - & 260 & 5 & 50 & 8 & 2 & 0.1 \\
\hline F12 & 24.75 & - & - & 230 & 10 & 50 & 8 & 2 & 0.1 \\
\hline F13 & 24.75 & - & - & 200 & 15 & 50 & 8 & 2 & 0.1 \\
\hline F14 & 24.75 & - & - & 170 & 20 & 50 & 8 & 2 & 0.1 \\
\hline F15 & 24.75 & - & - & 140 & 25 & 50 & 8 & 2 & 0.1 \\
\hline F16 & 24.75 & 260 & 50 & - & 5 & 50 & 8 & 2 & 0.1 \\
\hline F17 & 24.75 & 230 & 50 & - & 10 & 50 & 8 & 2 & 0.1 \\
\hline F18 & 24.75 & 200 & 50 & - & 15 & 50 & 8 & 2 & 0.1 \\
\hline F19 & 24.75 & 170 & 50 & - & 20 & 50 & 8 & 2 & 0.1 \\
\hline F20 & 24.75 & 140 & 50 & - & 25 & 50 & 8 & 2 & 0.1 \\
\hline F21 & 24.75 & 50 & - & 260 & 5 & 50 & 8 & 2 & 0.1 \\
\hline F22 & 24.75 & 50 & - & 230 & 10 & 50 & 8 & 2 & 0.1 \\
\hline F23 & 24.75 & 50 & - & 200 & 15 & 50 & 8 & 2 & 0.1 \\
\hline F24 & 24.75 & 50 & - & 170 & 20 & 50 & 8 & 2 & 0.1 \\
\hline F25 & 24.75 & 50 & - & 140 & 25 & 50 & 8 & 2 & 0.1 \\
\hline F26 & 24.75 & - & 260 & 50 & 5 & 50 & 8 & 2 & 0.1 \\
\hline F27 & 24.75 & - & 230 & 50 & 10 & 50 & 8 & 2 & 0.1 \\
\hline F28 & 24.75 & - & 200 & 50 & 15 & 50 & 8 & 2 & 0.1 \\
\hline F29 & 24.75 & - & 170 & 50 & 20 & 50 & 8 & 2 & 0.1 \\
\hline F30 & 24.75 & - & 140 & - & 25 & 50 & 8 & 2 & 0.1 \\
\hline
\end{tabular}

applied load at rupture divided by the strip cross-sectional area given in the equation below from the formula

$$
\text { Tensile strength }=\frac{\text { Load at the point of rupture }}{\text { Film thickness } \times \text { film width }}
$$

\section{Drug content}

A MX-ODF was transferred into a beaker containing $100 \mathrm{~mL}$ of the $\mathrm{pH}$ 6.8 phosphate buffer and was subjected to constant stirring for $2 \mathrm{hr} .{ }^{19}$ The dispersion after filtering was analyzed for the content of Meloxicam using UV-Visible spectrophotometer after suitable dilutions at a wavelength of $362 \mathrm{~nm}$. The test was performed in triplicate and the results reported were the mean values. 


\section{Disintegration time}

The disintegration time of the MX-ODFs was determined using Petri dish method..$^{20} 10 \mathrm{~mL}$ distilled water was transferred into the petri dishes and the ODFs of $4 \mathrm{~cm}^{2}$ were placed in each petri plate. The time at which the MX-ODFs were completely dispersed was taken as disintegration time. The test was performed in triplicate and the results were expressed as the mean of the three values \pm SD. ${ }^{21}$

\section{Dissolution study}

The dissolution test was conducted in USP type I basket apparatus. $900 \mathrm{~mL}$ of $6.8 \mathrm{pH}$ phosphate buffer of $900 \mathrm{~mL}$ was taken as the dissolution medium. ${ }^{22,23}$ Each film (equivalent to $7.5 \mathrm{mg}$ Meloxicam) was placed in the dissolution medium and after 1, 3, 5, 7, 9 and $10 \mathrm{~min}$, the samples were collected and replaced with the same buffer. The obtained samples were analyzed under spectrophotometrically under UV at a $\lambda_{\max }$ of $362 \mathrm{~nm}$.

\section{RESULTS}

\section{Appearance and Thickness}

The developed ODFs were visually observed for a smooth, uniform and transparent texture. The results of various physical characterization studies were shown in Table 2.

\section{Folding endurance}

The folding endurance values of the formulated ODFs ranged from 94 to 115 as shown in Table 2. The folding endurance of the meloxicam OFDs F1-F5 was in the range of 95-98, F6-F10 was in between 94-97, F11-F15 was $101-104, \mathrm{~F} 16-\mathrm{F} 20$ was $104-107, \mathrm{~F} 21-\mathrm{F} 25$ was in a range of 107-110, F26-F30 was between 108-115.

\section{Tensile strength}

From the results of the Tensile strength shown in Table 2. It was elucidated from these results that the tensile strength values ranged in between 118 to $428 \mathrm{G}$ which elucidates that formulated films were flexible with a good elasticity owing to the prevention of breaking upon handling.

\section{Drug content}

The contents of Meloxicam in all the formulated of MX-ODFs were observed to be in the range of $96.26 \%-98.90 \%$ as shown in Table 2 .

\section{Disintegration time}

It was observed that disintegration time of the Meloxicam MDFs films varies from $8 \mathrm{sec}$ to $15 \mathrm{sec}$ as shown in Table 2. The contour plot depicting the effect of amount of film former (HPMC E15+E3) and plasticizer (PEG 400) on the disintegration time of formulation F25 was indicated in Figure 1.

\section{Dissolution studies}

The dissolution profiles of Meloxicam were shown in Figure 2. The D5\% values for MX-ODFS were presented in Table 2 and the contour plot depicting the effect of amount of film former (HPMC E15+E3) and plasticizer (PEG 400) on the disintegration time of formulation F25 was indicated in Figure 2.

\section{Design validation and optimization}

The ANOVA studies on the four responses indicated that the selected model along with the factors $\mathrm{A}, \mathrm{B}$ and $\mathrm{C}$ were found to be significant for DT, Tensile strength and Folding endurance whereas the factor A was found to be insignificant in case of amount of drug dissolved after $5 \mathrm{mins}$ $(p>0.05)$ as shown in Table 3. To identify the ODFs formulation having
Table 2: Results* of various characterization studies of Meloxicam ODFs F1 - F30.

\begin{tabular}{|c|c|c|c|c|c|c|}
\hline \multirow[t]{2}{*}{ Code } & \multicolumn{6}{|c|}{ Evaluation Parameters } \\
\hline & $\begin{array}{c}\text { Thickness } \\
(\mathrm{mm})\end{array}$ & $\begin{array}{c}\text { Tensile } \\
\text { strength } \\
\text { (G) }\end{array}$ & $\begin{array}{c}\text { Folding } \\
\text { endurance }\end{array}$ & $\begin{array}{c}\text { DT } \\
\text { (sec.) }\end{array}$ & $\begin{array}{c}\text { Drug } \\
\text { content } \\
(\%)\end{array}$ & $\begin{array}{c}\text { Drug } \\
\text { release } \\
\text { after } 5 \mathrm{~min} \\
(\mathrm{D} 5 \%)\end{array}$ \\
\hline F1 & $0.235 \pm 0.03$ & & $98 \pm 5$ & $12 \pm 0.5$ & $98.69 \pm 0.23$ & $59.14 \pm 0.64$ \\
\hline $\mathrm{F} 2$ & $0.225 \pm 0.08$ & $220 \pm 6$ & $97 \pm 4$ & $12 \pm 0.4$ & $98.86 \pm 0.64$ & $59.57 \pm 0.21$ \\
\hline F3 & $0.222 \pm 0.01$ & $217 \pm 7$ & $97 \pm 3$ & $11 \pm 0.3$ & $98.33 \pm 0.06$ & $63.89 \pm 0.25$ \\
\hline $\mathrm{F} 4$ & $0.221 \pm 0.09$ & $179 \pm 5$ & $96 \pm 4$ & $11 \pm 0.3$ & $98.76 \pm 0.98$ & $68.76 \pm 0.75$ \\
\hline F5 & $0.220 \pm 0.06$ & $118 \pm 8$ & $95 \pm 5$ & $10 \pm 0.4$ & $98.70 \pm 0.68$ & $71.58 \pm 0.42$ \\
\hline F6 & $0.237 \pm 0.06$ & $289 \pm 3$ & $97 \pm 2$ & $14 \pm 0.5$ & $97.79 \pm 0.35$ & $48.56 \pm 0.52$ \\
\hline F7 & $0.235 \pm 0.05$ & $282 \pm 7$ & $96 \pm 1$ & $13 \pm 0.4$ & $95.46 \pm 0.23$ & $58.49 \pm 0.68$ \\
\hline F8 & $0.227 \pm 0.04$ & $269 \pm 6$ & $95 \pm 3$ & $12 \pm 0.4$ & $97.20 \pm 0.89$ & $65.35 \pm 0.38$ \\
\hline F9 & $0.225 \pm 0.02$ & $191 \pm 5$ & $95 \pm 3$ & $12 \pm 0.3$ & $97.89 \pm 0.78$ & $68.5 \pm 0.19$ \\
\hline F10 & $0.220 \pm 0.06$ & $180 \pm 8$ & $94 \pm 2$ & $11 \pm 0.3$ & $98.38 \pm 0.45$ & $67.89 \pm 0.35$ \\
\hline F11 & $0.227 \pm 0.07$ & $348 \pm 2$ & $104 \pm 5$ & $14 \pm 0.4$ & $96.25 \pm 0.44$ & $56.43 \pm 0.22$ \\
\hline F12 & $0.225 \pm 0.01$ & $311 \pm 7$ & $104 \pm 4$ & $13 \pm 0.3$ & $95.90 \pm 0.66$ & $59.86 \pm 0.15$ \\
\hline F13 & $0.220 \pm 0.06$ & $288 \pm 9$ & $103 \pm 3$ & $13 \pm 0.4$ & $96.42 \pm 0.69$ & $65.12 \pm 0.72$ \\
\hline F14 & $0.214 \pm 0.03$ & $212 \pm 5$ & $102 \pm 1$ & $12 \pm 0.4$ & $98.92 \pm 0.95$ & $69.32 \pm 0.68$ \\
\hline F15 & $0.210 \pm 0.09$ & $179 \pm 5$ & & $12 \pm 0.5$ & $98.09 \pm 0.24$ & $73.24 \pm 0.54$ \\
\hline F16 & $0.228 \pm 0.04$ & $369 \pm 4$ & $107 \pm 5$ & $15 \pm 0.4$ & $98.49 \pm 0.45$ & $60.12 \pm 0.29$ \\
\hline F17 & $0.226 \pm 0.09$ & $321 \pm 7$ & $107 \pm 4$ & $14 \pm 0.5$ & $97.78 \pm 0.56$ & $67.75 \pm 0.42$ \\
\hline F18 & $0.225 \pm 0.03$ & $280 \pm 8$ & $105 \pm 1$ & $14 \pm 0.3$ & $97.66 \pm 0.80$ & $68.46 \pm 0.51$ \\
\hline F19 & $0.224 \pm 0.05$ & $219 \pm 8$ & $105 \pm 3$ & $13 \pm 0.2$ & $96.76 \pm 0.91$ & $69.79 \pm 0.16$ \\
\hline $\mathrm{F} 20$ & $0.213 \pm 0.09$ & $191 \pm 6$ & $104 \pm 2$ & $13 \pm 0.2$ & $98.16 \pm 0.87$ & $82.78 \pm 0.32$ \\
\hline F21 & $0.226 \pm 0.03$ & $419 \pm 5$ & $107 \pm 3$ & $11 \pm 0.5$ & $97.58 \pm 0.30$ & $54.55 \pm 0.71$ \\
\hline $\mathrm{F} 22$ & $0.224 \pm 0.02$ & $426 \pm 7$ & $108 \pm 4$ & $11 \pm 0.4$ & $97.59 \pm 0.88$ & $59.25 \pm 0.81$ \\
\hline F23 & $0.239 \pm 0.19$ & $435 \pm 8$ & $108 \pm 1$ & $10 \pm 0.3$ & $95.26 \pm 0.77$ & $62.74 \pm 0.66$ \\
\hline F24 & $0.227 \pm 0.19$ & $441 \pm 4$ & $109 \pm 3$ & $10 \pm 0.5$ & $96.59 \pm 0.98$ & $62.55 \pm 0.53$ \\
\hline F25 & $0.217 \pm 0.09$ & $445 \pm 9$ & $110 \pm 5$ & $8 \pm 0.4$ & $98.90 \pm 0.27$ & $66.75 \pm 0.92$ \\
\hline F26 & $0.239 \pm 0.16$ & $405 \pm 6$ & $108 \pm 2$ & $11 \pm 0.4$ & $97.57 \pm 0.43$ & $57.95 \pm 0.19$ \\
\hline F27 & $0.238 \pm 0.18$ & $429 \pm 9$ & $106 \pm 4$ & $10 \pm 0.3$ & $96.70 \pm 0.52$ & $64.22 \pm 0.72$ \\
\hline F28 & $0.229 \pm 0.15$ & $435 \pm 6$ & $105 \pm 5$ & $10 \pm 0.2$ & $97.90 \pm 0.71$ & $79.56 \pm 0.57$ \\
\hline F29 & $0.219 \pm 0.78$ & $440 \pm 7$ & $115 \pm 2$ & $9 \pm 0.2$ & $96.78 \pm 0.61$ & $98.17 \pm 0.34$ \\
\hline F30 & $0.202 \pm 0.07$ & $428 \pm 5$ & $109 \pm 3$ & $9 \pm 0.3$ & $97.33 \pm 0.88$ & $64.56 \pm 0.32$ \\
\hline
\end{tabular}

* All the results were indicated as Average \pm Std. Dev. for $n=3$

desired responses, the optimization was carried by desirability functions approach using the Design Expert software.

\section{DISCUSSION}

The thickness values of all the MX-ODFs were found to be in a range of 0.202 to $0.238 \mathrm{~mm}$. The results elucidate that with the increase in the concentration of the film former, the thickness of ODF was found to be increased. This could be due to the increased viscosity of the pre-casted formulation mixture at higher polymer concentrations. ${ }^{5,7}$ The thickness of the optimized formulation was found to be $0.217 \pm 0.09 \mathrm{~mm}$. The study elucidates that with the increase in the concentration of polymer and plasticizer, folding endurance of mouth dissolving film increases which might be attributed to the increase in the elasticity and flexibility due to the plasticizer. 


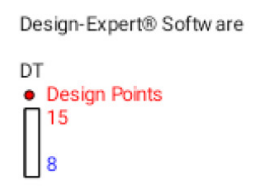

$\mathrm{X} 1=\mathrm{A}: \mathrm{HPMC}$ $\mathrm{X} 2=\mathrm{B}: \mathrm{PEG} 400$

Actual Factor C: Type of $H P M C=E 15+E 3$

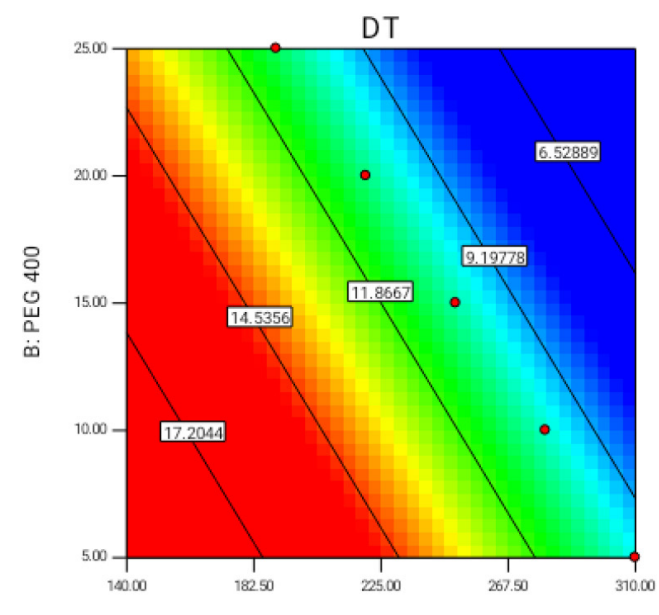

A. HPMC

Figure 1: Contour plots depicting the effect of the formulation factors Concentration of polymer and plasticizer on the Disintegration time.
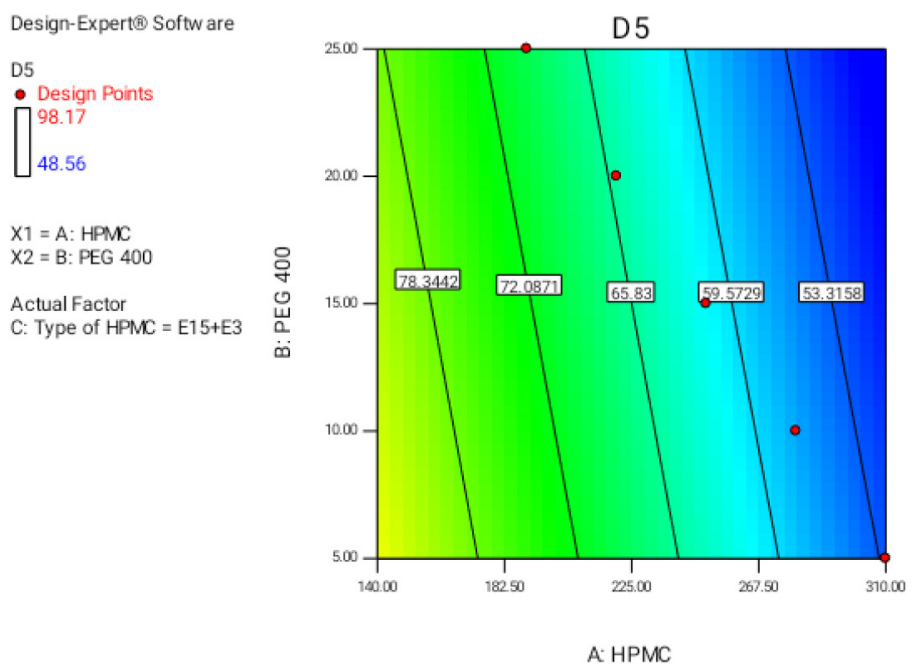

Figure 2: Contour plots depicting the effect of the formulation factors Concentration of polymer and plasticizer on the Dissolution after $5 \mathrm{~min}$ (D5\%).

Table 3: ANOVA test results of the four response variables for response surface linear model.

\begin{tabular}{|c|c|c|c|c|c|c|c|}
\hline Response & Source & SS $^{\mathbf{a}}$ & $\mathrm{Df}^{\mathrm{b}}$ & MSS $^{c}$ & $F$ value & $p$-Value & Inference $^{d}$ \\
\hline \multirow{6}{*}{ DT } & Model & 73.66 & 7 & 10.52 & 10.95 & $<0.0001$ & Significant \\
\hline & A- Amount of HPMC & 14.04 & 1 & 14.04 & 14.61 & 0.0009 & Significant \\
\hline & B- Amount of PEG 400 & 8.04 & 1 & 8.04 & 8.37 & 0.0084 & Significant \\
\hline & C- Type of HPMC & 71.69 & 5 & 14.34 & 14.92 & $<0.0001$ & Significant \\
\hline & Residual & 21.14 & 22 & 0.96 & & & \\
\hline & Cor Total & 94.80 & 29 & & & & \\
\hline \multirow{6}{*}{ Tensile Strength } & Model & $2.278 \times 10^{5}$ & 7 & 32536.0 & 66.54 & $<0.0001$ & Significant \\
\hline & A- Amount of HPMC & 13224.21 & 1 & 13224.2 & 27.04 & $<0.0001$ & Significant \\
\hline & B- Amount of PEG 400 & 9580.74 & 1 & 9580.7 & 19.59 & 0.0002 & Significant \\
\hline & C- Type of HPMC & 78114.44 & 5 & 15622.9 & 31.95 & $<0.0001$ & Significant \\
\hline & Residual & 10757.39 & 22 & 488.97 & & & \\
\hline & Cor Total & $2.385 \times 10^{5}$ & 29 & & & & \\
\hline \multirow{6}{*}{ Folding endurance } & Model & 717.10 & 7 & 102.44 & 156.84 & $<0.0001$ & Significant \\
\hline & A- Amount of HPMC & 2.96 & 1 & 2.96 & 4.54 & 0.0446 & Significant \\
\hline & B- Amount of PEG 400 & 38.16 & 1 & 38.16 & 58.43 & $<0.0001$ & Significant \\
\hline & C- Type of HPMC & 488.27 & 5 & 97.65 & 149.51 & $<0.0001$ & Significant \\
\hline & Residual & 14.37 & 22 & 0.65 & & & \\
\hline & Cor Total & 731.47 & 29 & & & & \\
\hline \multirow{6}{*}{ D5\% } & Model & 2611.68 & 7 & 373.10 & 9.56 & $<0.0001$ & Significant \\
\hline & A- Amount of HPMC & 27.30 & 1 & 27.30 & 0.70 & 0.4119 & Insignificant \\
\hline & B- Amount of PEG 400 & 1156.56 & 1 & 1156.56 & 29.64 & $<0.0001$ & Significant \\
\hline & C- Type of HPMC & 639.93 & 5 & 127.99 & 3.28 & 0.0231 & Significant \\
\hline & Residual & 858.44 & 22 & 39.02 & & & \\
\hline & Cor Total & 3470.12 & 29 & & & & \\
\hline
\end{tabular}

Note: ${ }^{\mathrm{a}-S u m}$ of Squares; ${ }^{\mathrm{b}}$-Degrees of Freedom; ${ }^{\mathrm{c}}$-Mean Sum of Squares; ${ }^{\mathrm{d}}$-p-Value less than 0.05 indicates model terms are significant 
It can be inferred from the results of tensile strength that, the increase in the concentration of the plasticizer resulted in the increase in the tensile strength owing to the entwinement of the plasticizer with the film formers thereby reducing the brittleness of the ODFs similar to the results of Jayarao YR et al. (2014) ${ }^{24}$ and Sanyang ML et al. $(2016)^{25}$ The folding endurance and $\%$ elongation values were correlated proportionally with tensile strength and increased upon increase in the plasticizer concentration.

The results elucidate good content uniformity among all the films as there is no significant difference in the drug content among all the formulations. The drug content of all the formulations was found be within the limit. The in vitro disintegration time of Meloxicam was found to decrease with the increase in the concentration of the polymer, which might be attributed to the ease of the medium to reach the disintegrants as the polymers used are of low molecular hydrophilic polymers owing to easy penetration of the medium into the film similar to the findings of Roy et al. $(2009)^{26}$ and Swamy SK et al. 2016. ${ }^{27}$ The ANOVA results infer that all the factors play a significant effect on the disintegration time $(p<0.05)$ as shown in Table 3.

It can be inferred from the ANOVA study as shown in Table 3 that there is a significant effect of the type of polymer and the amount of plasticizer used on the dissolution of the drug $(p<0.05)$. The effect of the amount of HPMC used at these levels was found to be insignificant on the dissolution of Meloxicam $(p>0.05)$. From the effect of the factors on the dissolution time it can be inferred that with the increase in the amount of plasticizer or the viscosity of the film forming polymer, the amount of drug dissolved after 5 min was found to be decreased which might be attributed to the increase in the complexity of the film former matrix prepared from high viscous polymer solution. At high thickness of the films, a higher diffusion path lengths may delay the diffusion of the drug thereby its dissolution. The results obtained were correlated with those of Zhang L et al. 2018. ${ }^{28}$

All the four responses DT, folding endurance, tensile strength and D5\% when as minimum as possible may increase the dissolution thereby enhancing the bioavailability of Meloxicam. Hence, this was taken as the desirability to proceed for the optimization. Among the various combinations of formulations with all the formulation factors A: 140mg (HPMC E15) and 50mg (HPMC E3), B: $25 \mathrm{~mL}$ and C: HPMC E15+ E3, had the maximum desirability of 0.848 (Figure 2). It can be inferred from the overlay plot that any value of the factors which are present within the overlaid region (yellow region/design space) in the plot can be used to formulate the MX-ODFs to obtain desired responses by $84.8 \%$ accuracy as shown in Figure 3 and the overlay plot indicating the optimized design space in Figure 4.

\section{CONCLUSION}

Meloxicam ODFs were developed in an aim to improve its dissolution thereby enhancing the bioavailability of MX. Historical data designing was employed using three different formulation factors using Design Expert software. The physical characterization studies including the response variables of the ODFs have shown that the formulated films were efficient. The suggested optimized formulation of the ODFs with 50mg HPMC E3 and 140mg HPMC E15; 25mL of PEG 400 was developed, upon optimization by desirability functions approach has a maximum desirability of 0.848 . The ANOVA studies show the significant effect of all the three factors on the responses with a probability $<0.05$. The study elucidates the development of the MX-ODFs using these factors can produce desirable responses thereby improving the bioavailability by enhancing the dissolution of Meloxicam.

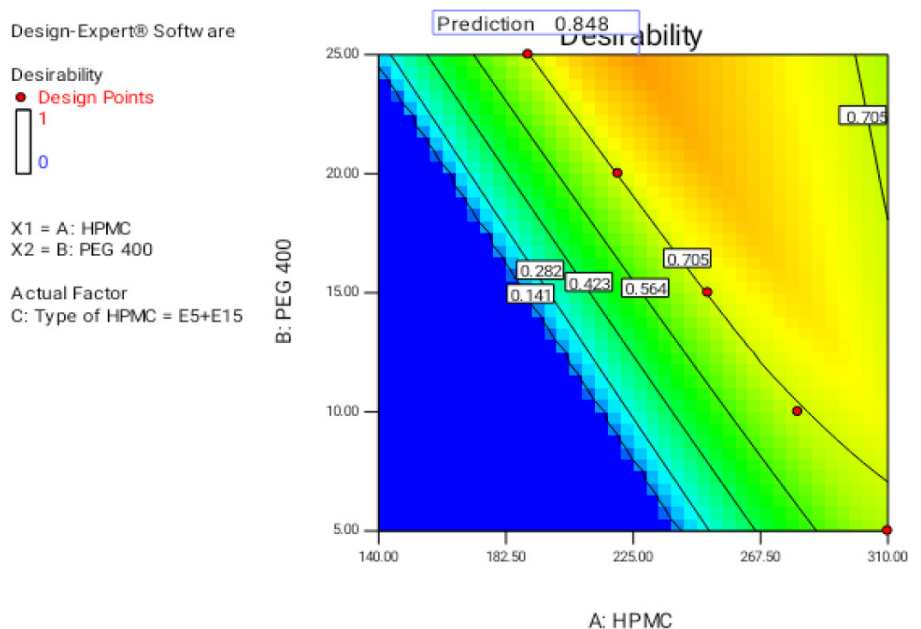

Figure 3: Desirability plot for the optimization.

Design-Expert@ Software

Overlay Plot

DT
D5

Ten. stren.

Ten. Stren.
Fold. End.

- Design Points

$X_{1}=A:$ HPMC

$\mathrm{X}_{1}=\mathrm{A}: \mathrm{HPMC}$
$\mathrm{X}_{2}=\mathrm{B}: \mathrm{PEG} 400$

Actual Factor

Actual Factor
C: Type of HPMC $=$ E5+E15

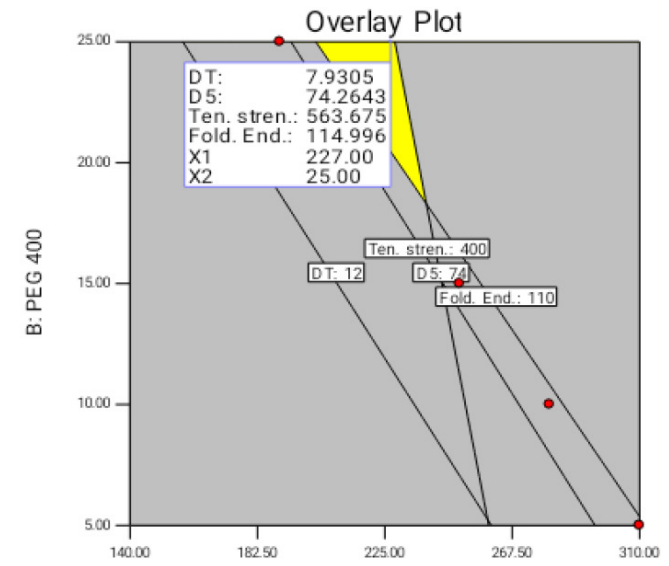

A: HPMC

Figure 4: Overlay plot indicating the design space and the optimized combination of the three factors and predicted response values.

\section{CONFLICT OF INTEREST}

The authors have no conflicts of interest regarding this investigation

\section{REFERENCES}

1. Türck $D$, Roth $W$, Busch $U$. A review of the clinical pharmacokinetics of meloxicam. $\mathrm{Br} J$ Rheumatol. 1996;35(1);Suppl 1:13-6. doi: 10.1093/ rheumatology/35.suppl_1.13, PMID 8630630.

2. Bekker A, Kloepping C, Collingwood S. Meloxicam in the management of postoperative pain: Narrative review. J Anaesthesiol Clin Pharmacol. 2018;34(4):450-7. doi: 10.4103/joacp.JOACP_133_18, PMID 30774225.

3. Ricciotti E, FitzGerald GA. Prostaglandins and inflammation. Arterioscler Thromb Vasc Biol. 2011;31(5):986-1000. doi: 10.1161/ATVBAHA.110.207449, PMID 21508345.

4. Tetko IV, Tanchuk VY, Kasheva TN, Villa AE. Estimation of aqueous solubility of chemical compounds using E-state indices. J. Chem. Inf. Comput. Sci. 2001;41:1488-93.

5. Hariharan M, Bogue A. Orally dissolving film strips (ODFS): The final evolution of orally dissolving dosage forms. Drug Deliv Technol. 2009;9(2):24-9.

6. Nishimura M, Matsuura K, Tsukioka T, Yamashita H, Inagaki N, Sugiyama T, et al. In vitro and in vivo characteristics of prochlorperazine oral disintegrating film. Int J Pharm. 2009;368(1-2):98-102. doi: 10.1016/j.ijpharm.2008.10.002, PMID 18992311. 
7. Keshavarao KP, Mudit D, Gunashekara K, Anis S, Mangla NS, Ajay K. Formulation and evaluation of mouth dissolving film containing rofecoxib. IRJP. 2011;2(3):273-8

8. Saini S, Samta A, Rana C, Gupta S. Optimization of formulation of fast dissolving films made of pullulan polymer. Int J Pharm Sci Rev Res. 2011;9(1):127-31.

9. Tiwari G, Tiwari R, Rai AK. Cyclodextrins in delivery systems: Applications. J Pharm Bioallied Sci. 2010;2(2):72-9. doi: 10.4103/0975-7406.67003, PMID 21814436.

10. Archontaki HA, Vertzoni MV, Athanassiou-Malaki MH. Study on the inclusion complexes of Bromazepam with beta- and beta-hydroxypropyl-cyclodextrins. J Pharm Biomed Anal. 2002;28(3-4):761-9. doi: 10.1016/s0731-7085(01)00679-3, PMID 12008156.

11. Marshall JJ, Miwa I. Kinetic difference between hydrolyses of gammacyclodextrin by human salivary and pancreatic alpha-amylases. Biochim Biophys Acta. 1981;661(1):142-7. doi: 10.1016/0005-2744(81)90093-0, PMID 6170334.

12. Preis $M$, Eckert $C$, Häusler $O$, Breitkreutz J. A comparative study on solubilizing and taste-masking capacities of hydroxypropyl- $\beta$-cyclodextrin and maltodextrins with high amylose content. Sens Actuators B. 2014;193:442-50. doi: 10.1016/j. snb.2013.12.005.

13. Del Valle EMM. Cyclodextrins and their uses: A review. Process Biochem. 2004;39(9):1033-46. doi: 10.1016/S0032-9592(03)00258-9.

14. Pereva S, Sarafska T, Bogdanova S, Spassov T. Efficiency of "cyclodextrinibuprofen" inclusion complex formation. J Drug Deliv Sci Technol. 2016;35:34-9. doi: 10.1016/j.jddst.2016.04.006.

15. Prabhu SC, Parsekar SD, Shetty A, Monteiro SS, Azharuddin M, Shabaraya AR. A review on fast dissolving sublingual films for systemic drug delivery. Int $J$ Pharm Chem Sci. 2014;3(2):501-11.

16. Rekha MR, Sharma CP. Pullulan as a promising biomaterial for biomedical applications: A perspective. Trends Biomater Artif Organs. 2007;20(2):116-21.

17. Entwistle CA, Rowe RC. Plasticization of cellulose ethers used in the film coating of tablets. J Pharm Pharmacol. 1979;31(5):269-72. doi: 10.1111/j.20427158.1979.tb13499.x, PMID 37293.

18. Patil PC, Shrivastava SK, S. V, P. A. Oral Fast Dissolving Drug Delivery System: A Modern Approach for Patient Compliance. Int J Drug Reg Affairs 2014;2(2):49-60. doi: 10.22270/ijdra.v2i2.131.
19. Nagar P, Chauhan I, Yasir M. Insights into polymers: Film formers in mouth dissolving films. Drug Invent Today. 2011;3(12):280-9.

20. Laohakunjit $N$, Noomhorm A. Effect of plasticizers on mechanical and barrier properties of rice starch film. Starch/Stärke. 2004;56(8):348-56. doi: 10.1002/ star.200300249

21. El-Setouhy DA, Abd El-Malak NS. Formulation of a novel tianeptine sodium orodispersible film. AAPS Pharm Sci Tech. 2010;11(3):1018-25. doi: 10.1208/ s12249-010-9464-2, PMID 20532710.

22. Kunte S, Tandale P. Fast dissolving strips: A novel approach for the delivery of verapamil. J Pharm Bioallied Sci. 2010;2(4):325-8. doi: 10.4103/09757406.72133, PMID 21180465.

23. Desu PK, Brahmaiah B, Nagalakshmi A, Neelima K, Nama S, et al. An overview on rapid dissolving films. Asian J Pharm Res. 2013;3:15-23.

24. Jayarao YR, Deborah D, Ambedhkar T, Manohar BS. Formulation and evaluation of fast dissolving oral films of perindopril. Res J Pharm Dosage Forms Technol. 2014:6(2):71-80

25. Sanyang ML, Sapuan SM, Jawaid M, Ishak MR, Sahari J. Effect of plasticizer type and concentration on physical properties of biodegradable films based on sugar palm (Arenga pinnata) starch for food packaging. J Food Sci Technol. 2016;53(1):326-36. doi: 10.1007/s13197-015-2009-7, PMID 26787952.

26. Roy A, Ghosh A, Datta S, Das S, Mohanraj P, Deb J, et al. Effects of plasticizers and surfactants on the film forming properties of hydroxypropyl methylcellulose for the coating of diclofenac sodium tablets. Saudi Pharm J. 2009;17(3):233-41. doi: 10.1016/j.jsps.2009.08.004, PMID 23964166.

27. Swamy SK, Arun G, Srinivas B, Goud AB. Effect of various super disintegrants on the drug release profile of orally disintegrating tablets. Asian Jour Pharm and Technol. 2016;6(2):99-105. doi: 10.5958/2231-5713.2016.00014.3.

28. Zhang L, Aloia M, Pielecha-Safira BP, Lin H, Rajai PM, Kunnath K, et al. Impact of Super disintegrants and Film Thickness on Disintegration Time of Strip Films Loaded With Poorly Water-Soluble Drug Microparticles. J Pharm Sci. 2018;107(8):2107-18. doi: 10.1016/j.xphs.2018.04.006, PMID 29665377.

Article History: Submission Date : 17-10-2021; Revised Date : 07-11-2021; Acceptance Date : 04-12-2021.

Cite this article: Nerella A, Nagabhushanam MV. Orodispersible Films of Meloxicam Inclusion Complexes for Bioavailability Enhancement: Optimization and Development through Quality by Design Approach. Int. J. Pharm. Investigation. 2021;11(4):420-5. 